\title{
Perspetiva sobre a gestão de uma organização de saúde
}

\author{
Denise Capela dos Santos
}

ORCID ID:0000-0002-5794-5203;

CIÊNCIA ID: 0B10-1C58-71EB, dsantos@autonoma.pt

Neste documento decidi, de forma muito sucinta, apresentar a minha visão de como a gestão de uma organização de saúde deverá contribuir para a sociedade, colaborando em simultâneo para o desempenho da organização e para a gestão da doença na comunidade.

O mercado da saúde apresenta grandes especificidades associadas ao valor da vida humana. As boas práticas de gestão em saúde e de organizações de saúde devem respeitar os princípios básicos da gestão mas devem, simultaneamente, dar prioridade aos ganhos em saúde da população. Num país com escassos recursos e a passar um momento bastante conturbado em termos de sustentabilidade económica e financeira, é preciso apostar cada vez mais no investimento direcionado ao que é efetivamente prioritário para a saúde, a nível local e em todo o território. Para isso, é preciso que as organizações de saúde estejam atentas aos eixos estratégicos e às grandes metas do Plano Nacional de Saúde em vigor (Plano Nacional de Saúde 2012-2016 com extensão a 2020, em linha com as orientações do Gabinete Europa da OMS para o Projeto "Health 2020"). As prioridades em saúde e metas definidas no Plano Local de Saúde devem ser consideradas na construção do planeamento estratégico de todas as organizações de saúde que se situem na zona geográfica delimitada para o respetivo ACES ou ULS (e apenas quando não é possível, para a região da ARS correspondente, considerando o Plano Regional de Saúde em vez do Plano Local de Saúde).

É com base nestas prioridades estabelecidas que as organizações devem, por local, e em equipa, participar na recolha de dados epidemiológicos que devem ser tratados pelo Observatório Local (pertencente a ACES e ULS), Regional (pertencente às ARS) ou Nacional (ACSS e INE) de Saúde.

Considerando os resultados da recolha de dados epidemiológicos, as organizações devem refletir sobre as necessidades em saúde mais evidentes da população envolvente, e sobre os fatores protetores e de risco locais, por patologia prioritária. É também com base nestes dados que, depois de avaliar os seus recursos financeiros, humanos, de instalações, de equipamentos e materiais, a gestão das organizações deverá realizar o planeamento operacional e a conceção e gestão do orçamento (não esquecendo o histórico de resultados). A gestão tem de adequar os seus recursos e de direcionar o investimento para a realização de atividades de promoção da 
Working Paper, Março 2019

Licenciatura em Administração de Unidades de Saúde

Departamento de Ciências Económicas e Empresariais

Universidade Autónoma de Lisboa

saúde, prevenção e tratamento das doenças com maior prevalência, maior incidência, maior taxa de mortalidade e morbilidade, da população envolvente.

Sabemos no entanto que, em saúde, a capacidade de resposta de tratamento de qualquer organização é limitada. De facto, no mercado da saúde há uma grande variedade de patologias (que podem ser crónicas ou surgir em fase aguda), sendo fundamental uma interação muito próxima de organizações especializadas em diferentes níveis de cuidados: primários, secundários e terciários. É então essencial que a organização realize protocolos com outras entidades com serviços complementares, do mesmo local ou região (dos setores público, privado e social) e que trabalhe muito bem em rede, contribuindo ativamente para salvaguardar a capacidade de resposta do sistema de saúde no país.

Assegurado o interesse nacional de gestão da doença, o foco do gestor deve ser o desempenho, nomeadamente em termos de produtividade aliada à qualidade, da sua organização. $\mathrm{O}$ desempenho de uma organização de saúde está relacionado com a capacidade estrutural dos serviços de saúde que presta face ao orçamento anual disponível para cumprimento da sua missão.

O gestor deverá preocupar-se primeiramente com a qualidade dos serviços prestados aos utentes, associada à qualidade do atendimento (empatia gerada entre os profissionais e os pacientes, e adequação do tempo de espera à gravidade da situação clínica), à exatidão do diagnóstico realizado, à eficácia terapêutica da medicação prescrita, à efetividade de outros tratamentos, e à disponibilidade de bons materiais, bons equipamentos e de instalações modernas. A gestão deve ainda incentivar a implementação de uma certificação da qualidade (associada à minimização de desperdício e à rentabilização de processos) em todos os serviços e deve mantê-la, assim como deve motivar toda a equipa para a melhoria sustentada dos processos (e eventualmente ponderar a sua acreditação por uma entidade externa).

Outra função de grande importância para o gestor de uma organização de saúde é a monitorização das metas e objetivos financeiros da organização. Para isso, para além do controlo assíduo de documentos contabilísticos, é fundamental que se tomem decisões com base em estudos de avaliação económica (análise clara e detalhada entre o custo para a organização e o benefício para os utentes) dos procedimentos técnicos a executar, de medicamentos a comprar, dos meios complementares de diagnóstico e terapêutica necessários realizar por diagnóstico, e dos equipamentos e materiais a comprar, por exemplo. Estes estudos devem ser realizados regularmente pela administração das organizações de saúde e divulgados aos profissionais de saúde, permitindo direcionar os recursos financeiros (maioritariamente escassos) para as maiores necessidades da organização.

Por fim, a gestão deve apostar e monitorizar a capacidade de aprendizagem, de inovação e de desenvolvimento dos profissionais (e da organização), sendo principalmente relevante dar primazia à motivação dos colaboradores (com atribuição de incentivos com base no seu desempenho individual e em equipa), assim como estimular o trabalho em equipa e o respeito 
Working Paper, Março 2019

Licenciatura em Administração de Unidades de Saúde

Departamento de Ciências Económicas e Empresariais

Universidade Autónoma de Lisboa

mútuo entre as diferentes classes profissionais, ou seja, é preciso apostar numa boa gestão do capital humano das organizações.

Se aliarmos estas práticas de gestão a uma boa comunicação dos resultados em saúde alcançados na comunidade (por patologia), e a uma intervenção ativa na população em atividades de promoção de saúde nas escolas e nas empresas locais, de forma sustentada, acredito estarem reunidas as condições para que tenhamos uma organização de saúde de sucesso, rentável, competitiva e de alta performance. 